Eric A. J. Hoste

Severine Doom

Jan De Waele

Louke J. Delrue

Luc Defreyne

Dominique D. Benoit

Johan Decruyenaere

\section{Epidemiology of contrast-associated acute
kidney injury in ICU patients: a retrospective \\ Epidemiology of contrast-associated acute
kidney injury in ICU patients: a retrospective cohort analysis} .

ved: 29 November 2010

Accepted: 29 April 2011

Published online: 3 November 2011

(C) Copyright jointly held by Springer and ESICM 2011

This article is discussed in the editorial available at:

doi:10.1007/s00134-011-2393-z.

\section{Electronic supplementary material}

The online version of this article

(doi:10.1007/s00134-011-2389-8) contains

supplementary material, which is available

to authorized users.

\author{
E. A. J. Hoste (-) S. Doom · \\ J. De Waele . D. D. Benoit . \\ J. Decruyenaere \\ Intensive Care Unit, ICU, 2K12 C, \\ Ghent University Hospital, \\ Ghent University, De Pintelaan 185, \\ 9000 Ghent, Belgium \\ e-mail: Eric.Hoste@UGent.be \\ Tel.: +32-9-3324197 \\ Fax: +32-9-3324995
}

\section{E. A. J. Hoste}

Research Foundation-Flanders (FWO),

Brussels, Belgium

\section{S. Doom}

Department of Anaesthesia,

Lievensberg Ziekenhuis,

Bergen op Zoom, The Netherlands

\section{J. Delrue}

Department of Radiology,

Ghent University Hospital,

Ghent University, Ghent, Belgium

\section{Defreyne}

Department of Interventional Radiology,

Ghent University Hospital,

Ghent University, Ghent, Belgium

Abstract Purpose: Intensive care unit (ICU) patients frequently undergo contrast-enhanced radiographic examinations, which carries a risk for development of contrastassociated acute kidney injury (CAAKI). Data on this in ICU patients are scarce. The aim of this study was therefore to evaluate the epidemiology and short- and long-term outcomes of CA-AKI in ICU patients. Methods: A retrospective singlecentre cohort study covering the period 1 March 2004 to 31 December 2008 on ICU patients who underwent a radiography examination with parenteral administration of iodinated radio contrast media was conducted. Data analysis included univariate and multivariate analyses of patients with and without CA-AKI. Results: A total of 787 ICU patients were included in the study. CA-AKI occurred in $128(16.3 \%)$ and was associated with higher need for RRT [30 (4.6\%) vs. $21(16.4 \%), p<0.001]$, worse kidney function at discharge, longer length of ICU and hospital stay, and higher 28-day and 1-year mortality [28-day:
$86(13.1 \%)$ vs. $46(35.9 \%)$, $p<0.001$, and 1-year: $158(24.0 \%)$ serum creatinine, lower mean arterial pressure, and administration of diuretics and vasoactive therapy were associated with development of CAAKI in multivariate analysis.After correction for confounders we found that CA-AKI was associated with 28-day mortality in this cohort of ICU patients (odds ratio $=2.742,95 \%$ confidence interval 1.374-5.471). Conclusions: CA-AKI occurred in one out of six ICU patients who underwent a contrast-enhanced radiography examination and was associated with both short-and longterm worse outcomes such as need for RRT, worse kidney function at discharge, increased length of stay in the ICU and hospital, and mortality.

Keywords Acute kidney injury/ acute renal failure - Hemodialysis . Contrast-induced acute kidney injury/ contrast nephropathy/contrastassociated acute kidney injury . Intensive care unit - Outcomes . Retrospective cohort study vs. $71(55.5 \%), p<0.001]$. Higher 


\section{Introduction}

Parenteral administration of iodine-containing radio contrast media in intensive care unit (ICU) patients may be associated with development of contrast-associated acute kidney injury (CA-AKI) [1-3]. We prefer to use the term "associated" instead of "contrast-induced" AKI because in the specific ICU setting development of AKI is most probably heterogeneous in origin [4]. Besides nephrotoxicity caused by contrast media, factors such as sepsis, hypotension, hypovolemia, and nephrotoxicity by, e.g., antibiotics may also play a role in the pathogenesis of AKI. When CA-AKI occurs it may have an important impact because it is associated with worse outcomes such as increase in length of hospital stay, complications, cost, and mortality. Levy et al. [5] assessed in their hallmark study the association of occurrence of CA-AKI and mortality. Even after correction for covariates they found an association of CA-AKI and death (odds ratio 5.5). This has since been reproduced by others in various settings [6-13].

The incidence of CA-AKI ranges between 0 and $50 \%$ depending on the case mix and the definition for CA-AKI that is used $[1,3,4,14,15]$. The most commonly used definition is an increase of serum creatinine $\geq 0.5 \mathrm{mg} / \mathrm{dL}$ or $\geq 25 \%$ from baseline, assessed $48-72 \mathrm{~h}$ after the procedure [16]. Recently, the Kidney Disease: Improving Global Outcomes (KDIGO) group defined a modified version of the definition for AKI that was previously developed by the Acute Dialysis Quality Initiative (ADQI) and the Acute Kidney Injury Network (AKIN) (http://www.KDIGO.org) [17, 18]. This consensus defines AKI as an increase of creatinine $\geq 0.3 \mathrm{mg} / \mathrm{dL}$ within a 48 -h period, or $\geq 50 \%$ compared to baseline within a 7-day period, or an episode of oliguria lasting $\geq 6 \mathrm{~h}$.

In a hospital-wide study, $11 \%$ of all episodes of AKI were contrast-associated, and contrast administration was the third most important cause of AKI [19]. The incidence in intensive care unit (ICU) patients with different risk profiles for CA-AKI is reported to be between 1.4 and $61 \%[20,21]$.

Despite being a well-known complication, data on CA-AKI in ICU patients are scarce, come from relative small datasets, and only report on short-term outcomes [20-25]. Therefore, the aim of this study was to assess the epidemiology and short- and long-term outcomes of CA-AKI in a large general ICU cohort.

\section{Materials and methods}

Setting and design

This is a retrospective single-centre study in a 56-bed teaching hospital ICU. The ICU consists of a 22-bed adult surgical ICU, a 14-bed medical ICU, an 8-bed cardiac surgery ICU, a 6-bed pediatric ICU, and a 6-bed burn unit.

\section{Data collection}

Data were retrieved from the electronic database of the Department of Radiology, the electronic ICU patient database management system (PDMS), the electronic patient file of the hospital, and the electronic hospital International Classification of Diseases version 9 (ICD-9) diagnosis database. The PDMS was introduced in the surgical ICU in 2003, the cardiac surgery ICU in 2005 , the medical ICU in 2006, the burn unit in 2007, and the pediatric ICU in 2008.

\section{Study population}

We included all ICU patients who underwent a diagnostic or therapeutic computed tomography (CT) scan or noncoronary angiography with intravenous or intra-arterial administration of iodinated contrast media during the period 1 March 2004 through 31 December 2008 and who had data recorded in the ICU PDMS. Only the first contrast administration was considered for this analysis. We excluded patients who had another intravenous or intraarterial iodinated contrast administration within a 3-day period after the index procedure. Also excluded were patients who were treated with renal replacement therapy (RRT) at time of contrast administration, and patients who had no serum creatinine concentrations recorded immediately before contrast administration.

\section{Processes of care}

Serum creatinine is measured routinely on a daily basis, and up to four times a day on clinical indication. Preventive measures for $\mathrm{CA}-\mathrm{AKI}$ are recommended in patients at risk for CA-AKI (eGFR $<60 \mathrm{~mL} / \mathrm{min}$ or creatinine $>1.2 \mathrm{mg} / \mathrm{dL}$ ) and consist of volume loading with isotonic saline or isotonic sodium bicarbonate according to the protocol of Merten et al. and/or administration of $\mathrm{N}$-acetylcysteine [26, 27].

Contrast media used during the study period were all nonionic, and iso-osmolar or low-osmolar. Angiography examinations were exclusively performed with a nonionic and iso-osmolar contrast agent (iodixanol).

Severity of illness at time of ICU admission was assessed by the APACHE II score [28]. Kidney function was assessed by serum creatinine concentration at time of ICU admission and at time of contrast administration. In addition, we estimated the glomerular filtration rate 
(eGFR) on the basis of the short re-expressed MDRD equation $[29,30]$.

At the time of contrast administration, we recorded concomitant administration of drugs that may increase the risk for development of CA-AKI. These included diuretic agents, angiotensin-converting enzyme inhibitors (ACEI), angiotensin II receptor blockers (ARB), amphotericin B (also included were the liposomal or lipid-coated forms), aminoglycosides, nonsteroidal anti-inflammatory drugs (NSAID), and acetylsalicylic acid.

Patients who were treated with norepinephrine, epinephrine, dopamine (in doses $>4 \mu \mathrm{g} / \mathrm{kg} / \mathrm{min}$ ), dobutamine, milrinone, or vasopressin were categorized as treated with vasoactive therapy.

Indications for renal replacement therapy (RRT) as well as the modality chosen [i.e., intermittent (duration 2-4 h per treatment session) or continuous hemodialysis (IHD/CHD), continuous veno-venous hemofiltration $(\mathrm{CVVH})$, or slow extended daily dialysis (SLEDD) (duration 6-12 h per treatment session)] were determined in consensus between the attending intensivist and nephrologist [31]. Criteria for initiation of RRT for AKI included volume overload and oliguria, acidosis, hyperkalemia, uremic symptoms, or uremia [32].

\section{Outcomes}

The primary outcome, CA-AKI, was defined as an increase of serum creatinine of $25 \%$ or $0.5 \mathrm{mg} / \mathrm{dL}$ or greater within 3 days after contrast administration [16]. Secondary outcomes included the KDIGO definition for AKI (a modification of the RIFLE and AKIN definition for AKI), defined as an increase of serum creatinine of $0.3 \mathrm{mg} / \mathrm{dL}$ or greater within a 48 -h period or $50 \%$ or greater increase from baseline within 7 days [17, 18]. Baseline creatinine was the lowest of serum creatinine on ICU admission and at time of contrast administration. This alternative definition was also measured during the 3 -day observation period. In addition, we recorded treatment with RRT, initiated during a 10-day period following contrast administration, length of ICU and hospital stay, and mortality at day 28 , day 60 , day 90 , 1 year, and at time of ICU and hospital discharge.

\section{Statistical analysis}

Data are reported as count (percentage) and median (25\% quartile, $75 \%$ quartile). Univariate analysis for continuous variables was with the Mann-Whitney $U$-test, and for categorical variables with the $\chi^{2}$ test. Survival analysis was performed with the Kaplan-Meier statistic and log rank test. Double-sided $p<0.05$ was considered as statistically significant.
Multivariate logistic regression analysis (enter method) was used for assessment of covariates that were associated with occurrence of CA-AKI and for covariates associated with 28-day mortality. Variables initially included in this analysis had a clinical plausible association and a $p$ value of $<0.25$ in univariate analysis. Correlation tables were used to assess co-linearity between variables. Interaction between variables was also evaluated. Final models were obtained by stepwise backward and forward selection of the variables (Wald method). For the mortality model, we also used a propensity score to correct for the risk of developing CA-AKI. This propensity score was developed with the model for development of CA-AKI. The models were evaluated with a goodness of fit test (Hosmer-Lemeshow), and the area under the curve (AUC) for the receiver operating characteristic (ROC) curve.

All statistical analyses were performed with the statistical software package SPSS, version 15.0 for Windows (SPSS, Chicago, IL, USA).

\section{Ethics approval}

The study was approved by the Ethics Committee of the Ghent University Hospital and conducted in accordance with the declaration of Helsinki. Informed consent was waived for this study.

\section{Results}

During the study period 18,866 patients were admitted to the ICU. Of these, 1,419 patients met the inclusion criteria for the study [Fig. 1 of the electronic supplementary material (ESM)]. After exclusion of 632 patients for various reasons, the final study cohort consisted of 787 patients. Median age of the patients was 59 years (46.5, 70.2), 490 were male (62.3\%), and the majority were admitted to the surgical ICU [surgical ICU 600 patients (76.2\%), medical ICU 159 (20.2\%), cardiac surgery ICU $23(2.9 \%)$, and pediatric ICU $5(0.6 \%)]$. The median length of stay between ICU admission and contrast administration was 2.6 days $(1.4,6.4)$. Contrast was administered for a contrast-enhanced CT scan in 619 patients $(78.7 \%)$; in 168 patients $(21.3 \%)$ the indication was angiography.

CA-AKI occurred in 128 patients (16.3\%). Severity of AKI in the majority of patients was limited to AKI stage 1; 31 patients (24.2\% of AKI patients) had severe AKI defined as AKI stage 3, of these, 14 patients (45.2\%) were treated with RRT. In one-quarter of patients, duration of AKI was 2 days or less (transient azotemia). When defined by the KDIGO definition for AKI, AKI was 
present in 175 patients (22.2\%). Compared to the definition used for the primary outcome, the KDIGO system was unable to detect 27 patients. On the other hand, KDIGO classified 74 patients as CA-AKI who remained undetected by the standard definition. Compared to the standard definition, KDIGO had a sensitivity of $78.9 \%$, specificity of $88.8 \%$, positive predictive value of $57.7 \%$, and negative predictive value of $95.6 \%$. Outcomes of patients who had CA-AKI as defined by KDIGO were comparable or even worse for relevant outcomes such as need for RRT and mortality (see Table 1 in the ESM).

\section{Comparison of patients with and without CA-AKI}

Serum creatinine peaked at day 2 after contrast administration in CA-AKI patients (Fig. 1). In patients without CA-AKI (no CA-AKI) we recorded a decrease of serum creatinine after contrast administration. Patients who developed CA-AKI were older, had a worse baseline kidney function, were more severely ill on admission, and a greater proportion were admitted to the medical ICU (Table 1). Higher CKD stages were associated with a higher occurrence rate of CA-AKI. The incidence of CA-AKI was comparable among patients who underwent a contrast-enhanced CT scan and those who underwent angiography (respectively 16.3 and $16.1 \%, p=0.966$ ). CA-AKI patients had a more positive volume balance and a lower urine output. At time of contrast administration, CA-AKI patients had lower hemoglobin concentration, a lower blood pressure, and a greater proportion were treated with vasoactive therapy and mechanical ventilation. They more frequently had a urinary sodium concentration below $20 \mathrm{mmol} / \mathrm{L}$, indicating prerenal azotemia and were more often treated with diuretic therapy. Finally, a greater proportion of CA-AKI patients were treated with drugs that may enhance the risk for CA-AKI.

After backward and forward stepwise selection of covariates in a multivariate logistic regression model, serum creatinine, administration of diuretics, lowest mean arterial blood pressure, and vasoactive therapy, all at day of contrast administration, were risk factors associated with occurrence of CA-AKI (Table 2).

\section{Preventive measures for CA-AKI}

Preventive measures for CA-AKI with $\mathrm{N}$-acetylcysteine or sodium bicarbonate were applied in 307 patients $(39.0 \%)$ of the whole study cohort. They were more frequently applied in risk patients. In patients with an eGFR $<60 \mathrm{~mL} / \mathrm{min}$ at time of admission and in patients with serum creatinine $>1.2 \mathrm{mg} / \mathrm{dL}$ at time of contrast administration, $130(61.3 \%)$ and 136 patients $(67.0 \%)$, respectively, received these therapies. There was a higher incidence of CA-AKI in patients who received preventive measures, especially in patients with CKD stages 1 or 2 (Table 2 of the ESM). There was no difference in occurrence rate of CA-AKI between patients with and
Fig. 1 Evolution of serum creatinine in patients without and with contrast-associated acute kidney injury (CA-AKI). creat Serum creatinine (mg/dL), $d$ day, $N$ number of recordings, $25 \% / 75 \%$ 25th and 75 th percentiles, respectively. $* P<0.001$ compared to creatinine before (Wilcoxon signed ranks test)
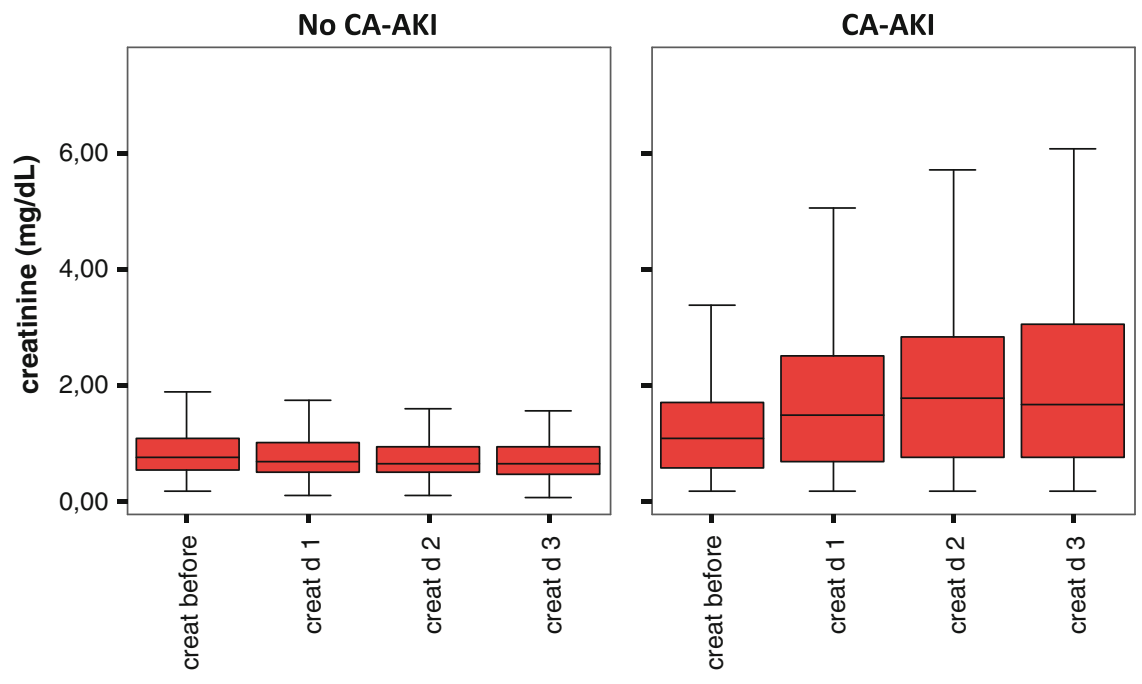

\begin{tabular}{|l|c|c|c|c|c|c|c|c|}
\hline & \multicolumn{4}{|c|}{ No CA-AKI } & \multicolumn{4}{c|}{ CA-AKI } \\
\hline & $\begin{array}{c}\text { Creat } \\
\text { before }\end{array}$ & $\begin{array}{c}\text { Creat } \\
\mathbf{d 1}\end{array}$ & $\begin{array}{c}\text { Creat } \\
\mathbf{d 2}\end{array}$ & $\begin{array}{c}\text { Creat } \\
\mathbf{d 3}\end{array}$ & $\begin{array}{c}\text { Creat } \\
\text { before }\end{array}$ & $\begin{array}{c}\text { Creat } \\
\mathbf{d 1}\end{array}$ & $\begin{array}{c}\text { Creat } \\
\mathbf{d 2}\end{array}$ & $\begin{array}{c}\text { Creat } \\
\text { d3* }\end{array}$ \\
\hline $\mathbf{N}$ & 659 & 647 & 651 & 544 & 128 & 126 & 127 & 108 \\
\hline Median & 0.77 & 0.68 & 0.65 & 0.64 & 1.11 & 1.50 & 1.77 & 1.69 \\
\hline $\mathbf{2 5 \%}$ & 0.55 & 0.51 & 0.49 & 0.48 & 0.58 & 0.70 & 0.75 & 0.76 \\
\hline $\mathbf{7 5 \%}$ & 1.09 & 1.01 & 0.94 & 0.94 & 1.73 & 2.52 & 2.86 & 3.07 \\
\hline
\end{tabular}


Table 1 Comparison of patients who developed contrast-associated acute kidney injury (CA-AKI) and those who did not (no CA-AKI)

\begin{tabular}{|c|c|c|c|}
\hline & No CA-AKI & CA-AKI & $P$ \\
\hline Number $(\%)$ & $659(83.5 \%)$ & $128(16.5 \%)$ & \\
\hline \multicolumn{4}{|l|}{ Data at time of ICU admission } \\
\hline Age (years) & $59(46.0,69.8)$ & $64(50.1,73.9)$ & 0.009 \\
\hline Male gender & $416(63.1 \%)$ & $74(57.8 \%)$ & 0.256 \\
\hline Diabetes & $82(12.4 \%)$ & $14(10.9 \%)$ & 0.634 \\
\hline Hypertension & $166(25.2 \%)$ & $38(29.7 \%)$ & 0.288 \\
\hline Heart failure & $55(8.3 \%)$ & $20(15.6 \%)$ & 0.010 \\
\hline Cirrhosis & $81(12.3 \%)$ & $23(18.0 \%)$ & 0.083 \\
\hline Creatinine $_{\text {admission }}(\mathrm{mg} / \mathrm{dL})(n=681)$ & $0.86(0.66,1.22)$ & $1.01(0.73,1.58)$ & 0.016 \\
\hline $\mathrm{eGFR}_{\text {admission }}\left(\mathrm{mL} / \mathrm{min} / 1.73 \mathrm{~m}^{2}\right)(n=681)$ & $84(55.6,113.6)$ & $70(41.6,96.3)$ & 0.006 \\
\hline $\mathrm{eGFR}_{\text {admission }}<60 \mathrm{~mL} / \mathrm{min} / 1.73 \mathrm{~m}^{2}(n=681)$ & $165(28.7 \%)$ & $46(43.4 \%)$ & 0.003 \\
\hline \multicolumn{4}{|l|}{ Chronic kidney disease stages $(n=681)$} \\
\hline CKD $1\left(\mathrm{eGFR}_{\text {admission }}>90 \mathrm{~mL} / \mathrm{min} / 1.73 \mathrm{~m}^{2}\right)$ & $249(43.3 \%)$ & $33(31.1 \%)$ & 0.045 \\
\hline CKD $2\left(\mathrm{eGFR}_{\text {admission }} 60-90 \mathrm{~mL} / \mathrm{min} / 1.73 \mathrm{~m}^{2}\right)$ & $161(28.0 \%)$ & $27(25.5 \%)$ & \\
\hline CKD $3\left(\mathrm{eGFR}_{\text {admission }} 30-60 \mathrm{~mL} / \mathrm{min} / 1.73 \mathrm{~m}^{2}\right)$ & $105(18.3 \%)$ & $30(28.3 \%)$ & \\
\hline CKD $4\left(\mathrm{eGFR}_{\text {admission }} 15-45 \mathrm{~mL} / \mathrm{min} / 1.73 \mathrm{~m}^{2}\right)$ & $44(7.7 \%)$ & $12(11.3 \%)$ & \\
\hline CKD $5\left(\right.$ eGFR admission $\left.<15 \mathrm{~mL} / \mathrm{min} / 1.73 \mathrm{~m}^{2}\right)$ & $16(2.8 \%)$ & $4(3.8 \%)$ & \\
\hline APACHE II score & $17(13,23)$ & $20(16,25)$ & 0.004 \\
\hline ICU unit & & & 0.015 \\
\hline Surgical ICU & $515(78.1 \%)$ & $85(66.4 \%)$ & \\
\hline Medical ICU & $125(19.0 \%)$ & $34(26.6 \%)$ & \\
\hline Cardiac surgery ICU & $16(2.4 \%)$ & $7(5.5 \%)$ & \\
\hline Pediatric ICU & $3(0.5 \%)$ & $2(1.6 \%)$ & \\
\hline Burn ICU & $0(0 \%)$ & $0(0 \%)$ & \\
\hline \multicolumn{4}{|l|}{ Data at time of contrast administration } \\
\hline Radiography examination & & & 0.939 \\
\hline CT scan & $518(83.7 \%)$ & $101(16.3 \%)$ & \\
\hline Angiography & $141(83.9 \%)$ & $27(16.1 \%)$ & \\
\hline LOS ICU before contrast administration (days) & $2.5(1.4,6.0)$ & $2.8(1.4,7.0)$ & 0.485 \\
\hline Creatinine (mg/dL) & $0.77(0.55,1.09)$ & $1.10(0.58,1.73)$ & $<0.001$ \\
\hline Creatinine $>1.5 \mathrm{mg} / \mathrm{dL}(\%)$ & $95(14.4 \%)$ & $44(34.4 \%)$ & $<0.001$ \\
\hline Urea (g/dL) & $0.41(0.28,0.73)$ & $0.61(0.38,0.95)$ & $<0.001$ \\
\hline Urine output (L/day) & $2.16(1.56,2.94)$ & $1.39(0.80,1.89)$ & $<0.001$ \\
\hline Volume balance (L/day) & $0.8(0.55,1.14)$ & $1.16(0.59,1.77)$ & $<0.001$ \\
\hline Positive volume balance & $501(76.4 \%)$ & $113(88.4 \%)$ & 0.003 \\
\hline Urine $\mathrm{Na}^{+}<20 \mathrm{mmol} / \mathrm{L}$ & $90(13.7 \%)$ & $32(25.0 \%)$ & 0.001 \\
\hline \multicolumn{4}{|l|}{ CA-AKI prevention } \\
\hline$N$-acetylcysteine & $165(25.0 \%)$ & $44(34.4 \%)$ & 0.029 \\
\hline $\mathrm{NaHCO}_{3}$ & $209(31.7 \%)$ & $59(46.1 \%)$ & 0.002 \\
\hline $\mathrm{N}$-acetylcysteine or $\mathrm{NaHCO}_{3}$ & $241(36.6 \%)$ & $66(51.6 \%)$ & 0.001 \\
\hline $\mathrm{N}$-acetylcysteine and $\mathrm{NaHCO}_{3}$ & $133(20.2 \%)$ & $37(28.9 \%)$ & 0.028 \\
\hline $\mathrm{N}$-acetylcysteine, no $\mathrm{NaHCO}_{3}$ & $32(4.9 \%)$ & $7(5.5 \%)$ & 0.770 \\
\hline $\mathrm{NaHCO}_{3}$, no $N$-acetylcysteine & $76(11.5 \%)$ & $22(17.2 \%)$ & 0.076 \\
\hline Minimum blood glucose (g/L) & $1.23(1.06,1.43)$ & $1.24(1.03,1.44)$ & 0.755 \\
\hline Treatment with insulin & $420(63.7 \%)$ & $92(71.9 \%)$ & 0.077 \\
\hline Insulin administered (U/day) & $28(13,50)$ & $31(18,56)$ & 0.116 \\
\hline Maximum rate of insulin infusion (U/h) & $2.5(1.5,4.0)$ & $2.8(2.0,4.0)$ & 0.142 \\
\hline Hemoglobin (g/dL) & $9.0(7.8,10.6)$ & $8.2(7.2,9.9)$ & $<0.001$ \\
\hline $\mathrm{Na}^{+}(\mathrm{mmol} / \mathrm{L})$ & $140(137,144)$ & $142(138,145)$ & 0.017 \\
\hline $\mathrm{MAP}_{\text {low }}(\mathrm{mmHg})$ & $72(64,83)$ & $65(57,77)$ & $<0.001$ \\
\hline Vasoactive therapy & $204(31.0 \%)$ & $64(50.0 \%)$ & $<0.001$ \\
\hline Mechanical ventilation & $333(50.5 \%)$ & $81(63.3 \%)$ & 0.008 \\
\hline Diuretic therapy & $169(25.6 \%)$ & $51(39.8 \%)$ & 0.001 \\
\hline ACEI or ARB & $49(7.4 \%)$ & $12(9.4 \%)$ & 0.453 \\
\hline Aminoglycosides & $2(0.3 \%)$ & $2(1.6 \%)$ & 0.067 \\
\hline Amphotericin & $0(0 \%)$ & $0(0 \%)$ & \\
\hline NSAID & $0(0 \%)$ & $0(0 \%)$ & \\
\hline Administration of drugs that $\uparrow$ risk CI-AKI ${ }^{\mathrm{a}}$ & $199(30.2 \%)$ & $56(43.8 \%)$ & 0.003 \\
\hline \multicolumn{4}{|l|}{ Kidney outcomes } \\
\hline Duration CA-AKI $\leq 2$ days & & $34(26.6 \%)$ & \\
\hline AKI class & & & $<0.001$ \\
\hline No AKI & $585(88.8 \%)$ & $27(21.1 \%)$ & \\
\hline Class 1 & $50(7.6 \%)$ & $47(36.7 \%)$ & \\
\hline
\end{tabular}


Table 1 continued

\begin{tabular}{|c|c|c|c|}
\hline & No CA-AKI & CA-AKI & $P$ \\
\hline Class 2 & $12(1.8 \%)$ & $23(18.0 \%)$ & \\
\hline Class 3 & $12(1.8 \%)$ & $31(24.2 \%)$ & \\
\hline $\mathrm{RRT} \leq 10$ days after contrast administration & $30(4.6 \%)$ & $21(16.4 \%)$ & $<0.001$ \\
\hline Duration of RRT (days) & $11(4,23)$ & $9(2,22)$ & 0.655 \\
\hline Number of RRT treatments & $7(2,13)$ & $7(2,17)$ & 0.850 \\
\hline RRT at time of hospital discharge & $0(0 \%)$ & $1(4.8 \%)$ & 0.227 \\
\hline Creatinine $_{\text {discharge }}(\mathrm{mg} / \mathrm{dL})$ & $0.57(0.43,0.78)$ & $0.91(0.52,1.90)$ & $<0.001$ \\
\hline $\mathrm{eGFR}_{\text {discharge }}\left(\mathrm{mL} / \mathrm{min} / 1.73 \mathrm{~m}^{2}\right)$ & $134(92.2,183.7)$ & $77(30.6,145.6)$ & $<0.001$ \\
\hline Creatinine $_{\text {discharge }}>$ creatinine before contrast & $121(18.4 \%)$ & $63(49.2 \%)$ & $<0.001$ \\
\hline \multicolumn{4}{|l|}{ Patient outcomes } \\
\hline LOS ICU (days) & $11(5.9,22.5)$ & $16(8.5,29.4)$ & 0.001 \\
\hline LOS ICU after contrast administration (days) & $8(4.2,16.2)$ & $12(5.1,24.1)$ & 0.002 \\
\hline LOS hospital after contrast administration (days) & $29(15.1,60.8)$ & $26(7.9,58.0)$ & 0.030 \\
\hline ICU mortality & $72(10.9 \%)$ & $45(35.2 \%)$ & $<0.001$ \\
\hline Mortality 28 days after contrast administration & $86(13.1 \%)$ & $46(35.9 \%)$ & $<0.001$ \\
\hline Mortality 60 days after contrast administration & $113(17.1 \%)$ & $57(44.5 \%)$ & $<0.001$ \\
\hline Mortality 90 days after contrast administration & $123(18.7 \%)$ & $61(47.7 \%)$ & $<0.001$ \\
\hline Mortality 1 year after contrast administration & $158(24.0 \%)$ & $71(55.5 \%)$ & $<0.001$ \\
\hline
\end{tabular}

Data are presented as $N(\%)$ or median (interquartile range)

length of stay, $M A P_{\text {low }}$ lowest mean arterial blood pressure, $A C E I$ $C A-A K I$ Contrast-associated acute kidney injury, $e G F R$ estimated angiotensin-converting enzyme inhibitor, $A R B$ angiotensin II glomerular filtration rate on basis of the modifying diet in renal receptor blocker, NSAID nonsteroidal anti-inflammatory drugs disease (MDRD) equation, $C K D$ chronic kidney disease, LOS ${ }^{a}$ Diuretic therapy, ACEI, ARB, amphotericin, or NSAID

Table 2 Variables associated with development of contrast-associated acute kidney injury according to a multivariate logistic regression analysis

\begin{tabular}{lcc}
\hline & Odds ratio & $95 \%$ CI \\
\hline Creatinine at time of contrast administration (per mg/dL) & 1.258 & $1.040,1.522$ \\
Diuretic therapy (yes) & 1.659 & $1.073,2.564$ \\
Vaso-active therapy (yes) & 1.890 & $1.205,2.965$ \\
Lowest MAP at time of contrast administration (per mmHg) & 0.978 & $0.961,0.995$ \\
Goodness of fit (according to Hosmer and Lemeshow): $\chi^{2}=7.874, \mathrm{df}=8, P=0.446$ & 0.006 \\
Percentage with correct prediction: $82.7 \%$ & & 0.013 \\
Area under the curve for the ROC curve $=0.69(0.631,0.741)$ & \\
\hline
\end{tabular}

$C I$ Confidence interval, $M A P$ mean arterial blood pressure, $R O C$ receiver operating characteristic

without preventive measures in the cohort of patients with CKD stages 3 or greater.

\section{Outcomes}

Compared to no CA-AKI patients, CA-AKI patients were at greater odds for needing treatment with RRT in the 10-day period following contrast administration [odds ratio (OR): 4.12, 95\% confidence interval (CI): 2.27-7.45] (Table 1). They also had worse kidney function at discharge, a greater proportion had a higher creatinine concentration at discharge compared to creatinine concentration at time of contrast administration, they had a longer length of stay, worse hospital survival (Fig. 2), and a higher mortality, up to 1 year after contrast administration [OR $(95 \% \mathrm{CI})$ for mortality in the ICU $=$ $4.42(2.85-6.85)$, at 28 days $=3.74(2.44-5.73)$, at 60 days $=3.88(2.59-5.81)$, at 90 days $=3.97(2.66-5.91)$, and at 1 year $=3.95(2.67-5.84)]$. Medical ICU patients had a nonsignificant trend for higher mortality between the 28-day and 1-year follow-ups (medical ICU $19.2 \%$ vs. surgical ICU $13.7 \%$ vs. cardiac surgery ICU $11.1 \%$, $p=0.267$ ). The KDIGO definition for CA-AKI was associated with similar differences in short- and long-term outcomes (Table 1 of the ESM). When stratified by eGFR on admission (higher or lower than 60 and $45 \mathrm{~mL} / \mathrm{min} /$ $1.73 \mathrm{~m}^{2}$ ), mortality was significantly higher for CA-AKI patients in both strata (data not shown).

\section{Association of CA-AKI and mortality}

In univariate analysis, nonsurvivors were older, had a greater severity of illness at time of ICU admission and at time of contrast administration, were more often medical ICU patients, and had worse kidney function (Table 3 ). Nonsurvivors also had a greater prevalence and severity 


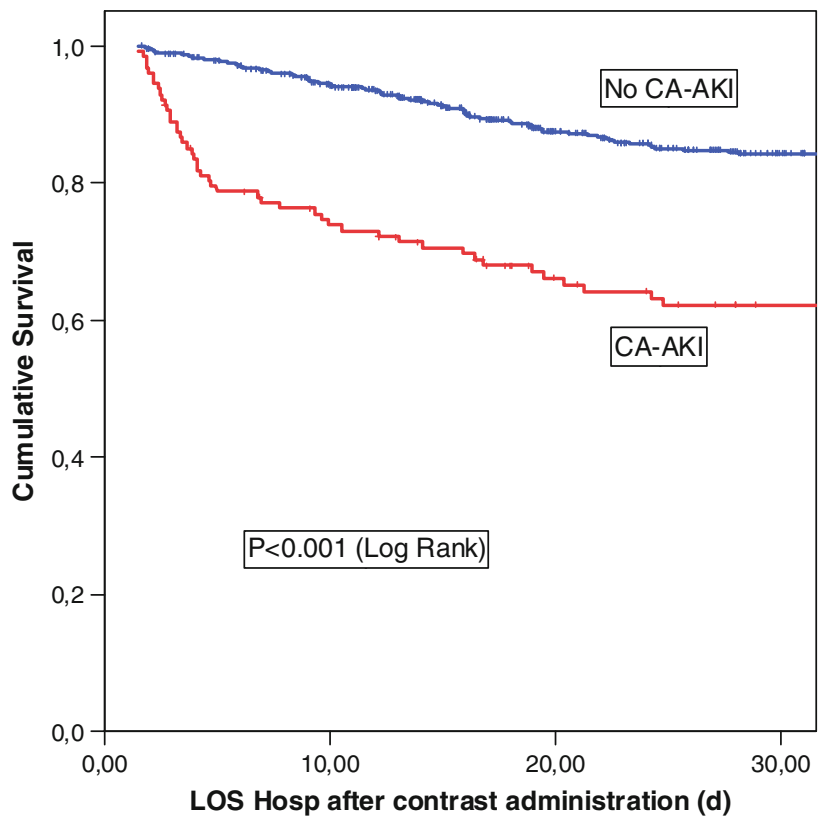

Fig. 2 Survival of patients without and with contrast-associated acute kidney injury (CA-AKI) LOS Hosp Length of stay in the hospital in days

of CA-AKI. When corrected for other covariates, for development of CA-AKI (with a propensity score), and for duration and severity of CA-AKI, we found that CAAKI was associated with 28-day mortality (Table 4).

\section{Discussion}

CA-AKI developed in one out of six ICU patients who were administered intravenous or intra-arterial radio contrast for a noncoronary angiography or CT scan. This was associated with worse short-term and long-term outcomes. CA-AKI patients were more frequently treated with RRT for AKI and had worse kidney function at ICU discharge. Furthermore, CA-AKI was associated with greater length of ICU and hospital stay, suggesting greater cost and resource use. Finally, mortality was higher in CA-AKI patients for up to 1 year after contrast administration.

The incidence of CA-AKI in this cohort of general ICU patients was higher than that reported in several other studies on this topic [20, 22-24], while others reported a similar or higher incidence $[21,25]$. It is very difficult to compare incidences in these studies because different definitions for CA-AKI were used, and specific cohorts were examined. The higher incidence in this study may be explained by the more sensitive definition for CA-AKI used compared to that in others (creatinine increase $>25 \%$ or $0.5 \mathrm{mg} / \mathrm{dL}$ compared to $0.5 \mathrm{mg} / \mathrm{dL}$ ) [20, 22, 23]. Also, a relative high number of patients had risk factors for development of CA-AKI in our study cohort. On the other hand, the higher incidence of CA-AKI in the study by Huber et al. [21] (61\%) may be explained by the higher risk profile for CA-AKI in that study, which included only patients with a baseline creatinine concentration of $2.5 \mathrm{mg} / \mathrm{dL}$.

Sixteen percent of CA-AKI patients were treated with RRT, which is nearly four times as many compared to patients without CA-AKI (16.4 vs. $4.6 \%)$. This is much higher compared to the incidence of RRT in non-ICU patients with CA-AKI, which is generally less than $1 \%$ in patients without risk factors and may increase to $4 \%$ in patients with underlying chronic kidney disease or patients undergoing primary PCI for acute coronary syndrome $[4,15,16]$. This high incidence can be explained by the greater severity of illness and resulting higher incidence of AKI in an ICU cohort. The 4\% incidence of RRT in patients without CA-AKI is comparable to that reported in ICU patients [33, 34]. Greater severity of illness is probably also the main determinant for greater severity of CA-AKI with need for RRT. This finding underlines the important impact of CA-AKI on outcome and on ICU health care resources. It also underlines the need for targeted strategies for prevention of CA-AKI in ICU patients.

The alternative definition for CA-AKI, the KDIGO modified RIFLE classification, had a higher sensitivity, which resulted in a higher incidence of CA-AKI, while relevant end points, such as short-term and long-term mortality were similar. This supports the use of this definition for CA-AKI as it may allow more early detection and intervention.

CA-AKI patients had a greater number of risk factors for development of CA-AKI. These included diabetes, hypertension, worse kidney function, lower urine output, prerenal characteristics, lower hemoglobin, and administration of drugs that enhance the risk for CA-AKI. They were also more severely ill on admission and at time of contrast administration (more were treated with vasoactive therapy and mechanical ventilation and blood pressure was lower), and a greater proportion were treated in the medical ICU. Although intravenous administration of radio contrast media probably carries a lower risk for CA-AKI compared to intra-arterial administration, we found that patients who underwent a CT scan (with intravenous contrast administration) carried a similar risk for CA-AKI compared to patients who underwent angiography (predominantly intra-arterial administration).

Preventive measures for development of CA-AKI, such as administration of $\mathrm{N}$-acetylcysteine or bicarbonate, were only undertaken in $60 \%$ of risk patients and were not associated with a lower occurrence rate of CA-AKI. Selection bias, resulting in administration of preventive therapy in patients who are at greatest risk for CA-AKI, may explain this. However, we cannot rule out that the 
Table 3 Survivors compared to nonsurvivors at 28 days after contrast administration

\begin{tabular}{|c|c|c|c|}
\hline & Survivors & Nonsurvivors & $P$ \\
\hline$N(\%)$ & $655(83.2 \%)$ & $132(16.8 \%)$ & \\
\hline \multicolumn{4}{|l|}{ Data at time of ICU admission } \\
\hline Age (years) & $58(44.8,69.3)$ & $64(51.3,72.4)$ & 0.001 \\
\hline Male gender & $413(63.1 \%)$ & $77(58.3 \%)$ & 0.307 \\
\hline Creatinine $_{\text {admission }}(\mathrm{mg} / \mathrm{dL})$ & $0.86(0.66,1.24)$ & $1.00(0.72,1.47)$ & 0.018 \\
\hline $\mathrm{eGFR}_{\text {admission }}\left(\mathrm{mL} / \mathrm{min} / 1.73 \mathrm{~m}^{2}\right)$ & $84(55.6,114.1)$ & $68(42.3,103.7)$ & $<0.001$ \\
\hline $\mathrm{eGFR}_{\text {admission }}<60 \mathrm{~mL} / \mathrm{min} / 1.73 \mathrm{~m}^{2}$ & $158(28.1 \%)$ & $53(40.2 \%)$ & $<0.001$ \\
\hline Diabetes & $81(12.4 \%)$ & $15(11.4 \%)$ & 0.748 \\
\hline Hypertension & $171(26.1 \%)$ & $33(25.0 \%)$ & 0.791 \\
\hline Heart failure & $50(7.6 \%)$ & $25(18.9 \%)$ & $<0.001$ \\
\hline Cirrhosis & $75(11.5 \%)$ & $29(22.0 \%)$ & 0.001 \\
\hline APACHE II score & $17(13.0,23.0)$ & $20(16.0,27.0)$ & $<0.001$ \\
\hline ICU & & & 0.006 \\
\hline Surgical ICU & $512(78.2 \%)$ & $88(66.7 \%)$ & \\
\hline Medical ICU & $118(18.0 \%)$ & $41(31.1 \%)$ & \\
\hline Cardiac surgery ICU & $20(3.1 \%)$ & $3(2.3 \%)$ & \\
\hline Pediatric ICU & $5(0.8 \%)$ & 0 & \\
\hline \multicolumn{4}{|l|}{ Data at time of contrast administration } \\
\hline Radiography examination & & & 0.057 \\
\hline CT scan & $507(77.4 \%)$ & $112(84.8 \%)$ & \\
\hline Angiography & $148(22.6 \%)$ & $20(15.2 \%)$ & \\
\hline LOS ICU before contrast (days) & $2.5(1.3,6.0)$ & $3.1(1.6,7.1)$ & 0.037 \\
\hline Creatinine (mg/dL) & $0.75(0.54,1.08)$ & $1.26(0.68,1.75)$ & $<0.001$ \\
\hline Urea $(\mathrm{g} / \mathrm{dL})$ & $0.41(0.28,0.71)$ & $0.68(0.42,1.06)$ & $<0.001$ \\
\hline Urine output (L/day) & $2.10(1.50,2.95)$ & $1.49(0.90,2.33)$ & $<0.001$ \\
\hline Volume balance (L/day) & $0.76(0.54,1.09)$ & $1.26(0.69,1.76)$ & $<0.001$ \\
\hline Positive volume balance & $494(75.7 \%)$ & $120(91.6 \%)$ & $<0.001$ \\
\hline Urine $\mathrm{Na}^{+}<20 \mathrm{mmol} / \mathrm{L}$ & $565(86.3 \%)$ & $100(75.8 \%)$ & 0.002 \\
\hline Treatment with insulin & $413(63.1 \%)$ & $99(75.0 \%)$ & 0.009 \\
\hline Hemoglobin (g/dL) & $8.9(7.8,10.6)$ & $8.7(7.6,10.0)$ & 0.086 \\
\hline $\mathrm{Na}^{+}(\mathrm{mmol} / \mathrm{L})$ & $140(137,144)$ & $141(138,145)$ & 0.085 \\
\hline $\mathrm{MAP}_{\text {low }}(\mathrm{mmHg})$ & $71(63.0,83.0)$ & $66(58.3,77.0)$ & $<0.001$ \\
\hline Vasoactive therapy & $202(30.8 \%)$ & $66(50.0 \%)$ & $<0.001$ \\
\hline Mechanical ventilation & $322(49.2 \%)$ & $92(69.7 \%)$ & $<0.001$ \\
\hline Diuretic therapy & $163(24.9 \%)$ & $57(43.2 \%)$ & $<0.001$ \\
\hline Administration of drugs that $\uparrow$ risk $\mathrm{CA}-\mathrm{AKI}^{\mathrm{a}}$ & $193(29.5 \%)$ & $62(47.0 \%)$ & $<0.001$ \\
\hline \multicolumn{4}{|l|}{ Kidney outcomes } \\
\hline CA-AKI & $82(12.5 \%)$ & $46(34.8 \%)$ & $<0.001$ \\
\hline Duration of CA-AKI (\% within CA-AKI) & & & 0.611 \\
\hline$\leq 2$ days & $23(28.0 \%)$ & $11(23.9 \%)$ & \\
\hline$>2$ days & $59(72.0 \%)$ & $35(76.1 \%)$ & \\
\hline AKI class & & & $<0.001$ \\
\hline No AKI & $544(83.1 \%)$ & $68(51.5 \%)$ & \\
\hline Class 1 & $62(9.5 \%)$ & $35(26.5 \%)$ & \\
\hline Class 2 & $18(2.7 \%)$ & $17(12.9 \%)$ & \\
\hline Class 3 & $31(4.7 \%)$ & $12(9.1 \%)$ & \\
\hline Renal replacement therapy & $27(4.1 \%)$ & $24(18.2 \%)$ & $<0.001$ \\
\hline
\end{tabular}

Data are presented as $N(\%)$ or median (interquartile range) $C A-A K I$ Contrast-associated acute kidney injury, $e G F R$ estimated glomerular filtration rate on basis of the modifying diet in renal disease (MDRD) equation, LOS length of stay, MAP low lowest mean arterial blood pressure, $A C E I$ angiotensin-converting enzyme inhibitor, $A R B$ angiotensin II receptor blocker, NSAID nonsteroidal anti-inflammatory drugs

a Diuretic therapy, ACEI, ARB, amphotericin, or NSAID complex and multifactorial pathophysiology of development of AKI in ICU patients precludes the beneficial effects of these therapies. Our data do therefore suggest the need for a prospective study on the effects of preventive measures in this specific cohort of ICU patients.

The strength of this study is that we specifically studied a cohort of ICU patients. ICU patients have a completely different risk profile for development of
CA-AKI compared to non-ICU patients. Therefore, epidemiologic data on CA-AKI in, e.g., hospitalized patients or patients who have undergone coronary angiography should not be translated to ICU patients who are administered radio contrast. The epidemiology of CA-AKI in an ICU setting was described in two other studies [20, 24]. Our study is a relevant addition to these. First, the two studies described a total of 470 patients, compared to 787 
Table 4 Association of contrast-associated acute kidney injury and 28-day mortality

\begin{tabular}{lllrr}
\hline & Odds ratio & $95 \%$ CI & $P$ & \multicolumn{1}{c}{ AUC ROC curve } \\
\hline Unadjusted & 3.738 & $2.440,5.725$ & $<0.001$ & $0.61(0.555,0.668)$ \\
Adjusted & 3.449 & $1.962,6.065$ & $<0.001$ & $0.734(0.683,0.785)$ \\
Model 1 & 3.302 & $1.786,6.104$ & $<0.001$ & $0.781(0.733,0.829)$ \\
Model 2 & 2.693 & $1.381,5.251$ & 0.004 & $0.795(0.745,0.845)$ \\
Model 3 & 2.742 & $1.374,5.471$ & 0.004 & $0.804(0.754,0.853)$ \\
Model 4 & 3.095 & $1.485,6.451$ & 0.003 & $0.806(0.757,0.855)$ \\
Model 5 & 3.032 & $1.447,6.352$ & 0.003 & $0.807(0.758,0.856)$ \\
Model 6 & & & 0.7567 \\
\hline
\end{tabular}

Covariates used for adjustment were as follows: Model 1 age, concentration, urinary sodium concentration $<20 \mathrm{mmol} / \mathrm{L}$, hemoAPACHE II score, ICU type; Model 2 covariates from model globin, insulin therapy); Model 5 covariates from model $1+$ heart failure, cirrhosis, creatinine on admission; Model $34+$ duration of CA-AKI $\leq 2$ days; Model 6 covariates from model covariates from model $2+$ propensity score for development of $5+$ renal replacement therapy

CA-AKI; Model 4 covariates from model $3+$ variables at time of $C I$ Confidence interval, $A U C$ area under the curve, $R O C$ receiver contrast administration (mechanical ventilation, vasoactive therapy, operating characteristic

type of radiographic examination, volume balance, sodium

patients in our study. Including a larger number of patients reduces bias and renders more relevant data. Second, both studies analyzed patients who were administered contrast in the setting of a CT scan examination. We also describe patients who underwent noncoronary angiography. Third, we did not restrict ourselves to reporting of ICU and hospital mortality but also reported on a whole set of kidney outcomes and 28-, 60-, 90-day, and 1-year mortality. Fourth, we are the first to compare the traditional and new definitions for CA-AKI. Finally, we did not restrict ourselves to a univariate comparison of patients with and without CA-AKI but provide on the basis of a very complete set of possible confounders a multivariate analysis for development of CA-AKI and six different multivariate models to evaluate the association of CA-AKI and mortality (including the use of a propensity correction).

Limitations include the single-centre retrospective design. Selection bias was a consequence of the gradual introduction of the PDMS. CA-AKI had a higher incidence in the medical ICU, which also had a shorter study period. The reported data therefore probably underestimate the true incidence of CA-AKI in a general ICU. Also, it is not certain if the occurrence of AKI in this cohort of ICU patients was caused by contrast administration or was the result of the underlying disease state (e.g., sepsis) or was the consequence of both. Especially in critically ill patients, many other factors may play a role, and AKI is most likely of heterogeneous origin. Future studies should aim to demonstrate that preventive measures that are specific to one of the possible underlying etiologies (e.g., contrast exposure) also impact on these outcomes in a cohort of ICU patients. In addition, despite the extensive dataset included in this database, we could not evaluate the effects of the volume of contrast administered. Further, long-term survival was based on administrative hospital data. These are accurate because the majority of our patients have in-hospital follow-up. However, we cannot exclude that there was loss of follow-up in a small minority of patients, which may have led to an underestimation of the reported long-term mortality. Finally, the retrospective data collection also precluded recording of data on the exact amount and type of contrast media administered.

\section{Conclusions}

CA-AKI occurred in one out of six ICU patients who underwent a contrast-enhanced noncoronary radiography examination and was associated with both short- and long-term worse outcomes such as need for RRT, worse kidney function at discharge, increased length of stay in the ICU and hospital, and mortality. Preventive measures were only used in two-thirds of risk patients and did not result in a lower incidence of CA-AKI. Increasing the sensitivity of the definition for CA-AKI by use of the KDIGO modified RIFLE classification renders equal relevant outcomes and may thus help in early detection and preventive measures.

Acknowledgments We wish to thank Mr. C. Danneels and Dr. E. Baert for providing the ICU-related data and the administrative data for this study. Eric Hoste is Senior Clinical Investigator of the Research Foundation-Flanders (Belgium) (FWO). 


\section{References}

1. McCullough PA, Adam A, Becker CR, Davidson C, Lameire N, Stacul F, Tumlin J (2006) Epidemiology and prognostic implications of contrastinduced nephropathy. Am J Cardiol 98(6 Suppl 1):5-13

2. McCullough PA, Stacul F, Becker CR, Adam A, Lameire N, Tumlin JA, Davidson CJ (2006) Contrast-Induced Nephropathy (CIN) Consensus Working Panel: executive summary. Rev Cardiovasc Med 7:177-197

3. Lameire N (2007) Contrast-induced nephropathy in the critically-ill patient: focus on emergency screening and prevention. Acta Clin Belg Suppl $2: 346-352$

4. Hoste EA, De Waele JJ, Gevaert SA, Uchino S, Kellum JA (2010) Sodium bicarbonate for prevention of contrastinduced acute kidney injury: a systematic review and meta-analysis. Nephrol Dial Transpl 25:747-758

5. Levy EM, Viscoli CM, Horwitz RI (1996) The effect of acute renal failure on mortality. A cohort analysis. JAMA 275:1489-1494

6. Rihal CS, Textor SC, Grill DE, Berger PB, Ting HH, Best PJ, Singh M, Bell MR, Barsness GW, Mathew V, Garratt KN, Holmes DRJ (2002) Incidence and prognostic importance of acute renal failure after percutaneous coronary intervention. Circulation 105:2259-2264

7. Gruberg L, Mintz GS, Mehran R, Gangas G, Lansky AJ, Kent KM, Pichard AD, Satler LF, Leon MB (2000) The prognostic implications of further renal function deterioration within $48 \mathrm{~h}$ of interventional coronary procedures in patients with pre-existent chronic renal insufficiency. J Am Coll Cardiol 36:1542-1548

8. Dangas G, Iakovou I, Nikolsky E, Aymong ED, Mintz GS, Kipshidze NN, Lansky AJ, Moussa I, Stone GW, Moses JW, Leon MB, Mehran R (2005) Contrast-induced nephropathy after percutaneous coronary interventions in relation to chronic kidney disease and hemodynamic variables. Am J Cardiol 95:13-19

9. Sadeghi HM, Stone GW, Grines CL, Mehran R, Dixon SR, Lansky AJ, Fahy M, Cox DA, Garcia E, Tcheng JE, Griffin JJ, Stuckey TD, Turco M, Carroll JD (2003) Impact of renal insufficiency in patients undergoing primary angioplasty for acute myocardial infarction. Circulation 108:2769-2775
10. Marenzi G, Lauri G, Assanelli E, Campodonico J, De Metrio M, Marana I, Grazi M, Veglia F, Bartorelli AL (2004) Contrast-induced nephropathy in patients undergoing primary angioplasty for acute myocardial infarction. J Am Coll Cardiol 44:1780-1785

11. Lindsay J, Apple S, Pinnow EE, Gevorkian N, Gruberg L, Satler LF, Pichard AD, Kent KM, Suddath W, Waksman R (2003) Percutaneous coronary intervention-associated nephropathy foreshadows increased risk of late adverse events in patients with normal baseline serum creatinine. Catheter Cardiovasc Interv 59:338-343

12. Nikolsky E, Mehran R, Turcot D, Aymong ED, Mintz GS, Lasic Z, Lansky AJ, Tsounias E, Moses JW, Stone GW, Leon MB, Dangas GD (2004) Impact of chronic kidney disease on prognosis of patients with diabetes mellitus treated with percutaneous coronary intervention. Am J Cardiol 94:300-305

13. Solomon RJ, Mehran R, Natarajan MK, Doucet S, Katholi RE, Staniloae CS, Sharma SK, Labinaz M, Gelormini JL, Barrett BJ (2009) Contrast-induced nephropathy and long-term adverse events: cause and effect? Clin J Am Soc Nephrol 4:1162-1169

14. McCullough PA, Adam A, Becker CR, Davidson C, Lameire N, Stacul F, Tumlin J (2006) Risk prediction of contrast-induced nephropathy. Am J Cardiol 98(6 Suppl 1):27-36

15. Joannidis M, Schmid M, Wiedermann CJ (2008) Prevention of contrast mediainduced nephropathy by isotonic sodium bicarbonate: a meta-analysis. Wien Klin Wochenschr 120:742-748

16. McCullough PA (2008) Contrastinduced acute kidney injury. J Am Coll Cardiol 51:1419-1428

17. Bellomo R, Ronco C, Kellum JA, Mehta RL, Palevsky P (2004) Acute renal failure-definition, outcome measures, animal models, fluid therapy and information technology needs: the Second International Consensus Conference of the Acute Dialysis Quality Initiative (ADQI) group. Crit Care 8:R204-R212

18. Mehta RL, Kellum JA, Shah SV, Molitoris BA, Ronco C, Warnock DG, Levin A (2007) Acute Kidney Injury Network: report of an initiative to improve outcomes in acute kidney injury. Crit Care 11:R31

19. Nash K, Hafeez A, Hou S (2002) Hospital-acquired renal insufficiency. Am J Kidney Dis 39:930-936
20. Haveman JW, Gansevoort RT, Bongaerts AH, Nijsten MW (2006) Low incidence of nephropathy in surgical ICU patients receiving intravenous contrast: a retrospective analysis. Intensive Care Med 32:1199-1205

21. Huber W, Jeschke B, Kreymann B, Hennig M, Page M, Salmhofer H, Eckel F, Schmidt U, Umgelter A, Schweigart U, Classen M (2002) Haemodialysis for the prevention of contrast-induced nephropathy: outcome of 31 patients with severely impaired renal function, comparison with patients at similar risk and review. Invest Radiol 37:471-481

22. Huber W, Eckel F, Hennig M, Rosenbrock H, Wacker A, Saur D, Sennefelder A, Hennico R, Schenk C, Meining A, Schmelz R, Fritsch R, Weiss W, Hamar P, Heemann U, Schmid RM (2006) Prophylaxis of contrast material-induced nephropathy in patients in intensive care: acetylcysteine, theophylline, or both? A randomized study. Radiology 239:793-804

23. Huber W, Jeschke B, Page M, Weiss W, Salmhofer H, Schweigart U, Ilgmann K, Reichenberger J, Neu B, Classen M (2001) Reduced incidence of radiocontrast-induced nephropathy in ICU patients under theophylline prophylaxis: a prospective comparison to series of patients at similar risk. Intensive Care Med 27:1200-1209

24. Rashid AH, Brieva JL, Stokes B (2009) Incidence of contrast-induced nephropathy in intensive care patients undergoing computerised tomography and prevalence of risk factors. Anaesth Intensive Care 37:968-975

25. Polena S, Yang S, Alam R, Gricius J, Gupta JR, Badalova N, Chuang P, Gintautas J, Conetta R (2005) Nephropathy in critically ill patients without preexisting renal disease. Proc West Pharmacol Soc 48:134-135

26. Merten GJ, Burgess WP, Gray LV, Holleman JH, Roush TS, Kowalchuk GJ, Bersin RM, Van Moore A, Simonton CA III, Rittase RA, Norton HJ, Kennedy TP (2004) Prevention of contrast-induced nephropathy with sodium bicarbonate: a randomized controlled trial. JAMA 291:2328-2334

27. Tepel M, van der Giet M, Schwarzfeld C, Laufer U, Liermann D, Zidek W (2000) Prevention of radiographiccontrast-agent-induced reductions in renal function by acetylcysteine. N Engl J Med 343:180-184 
28. Knaus WA, Draper EA, Wagner DP, Zimmerman JE (1985) APACHE II: a severity of disease classification system. Crit Care Med 13:818-829

29. Levey AS, Greene T, Kusek JW, Beck GJ, MDRD Study Group (2000) A simplified equation to predict glomerular filtration rate from serum creatinine. J Am Soc Nephrol 11:A0828

30. Levey AS, Coresh J, Greene T, Marsh J, Stevens LA, Kusek JW, Van Lente F (2007) Expressing the Modification of Diet in Renal Disease Study equation for estimating glomerular filtration rate with standardized serum creatinine values. Clin Chem 53:766-772
31. Reynvoet E, Vandijck DM, Blot SI, Dhondt AW, De Waele JJ, Claus S, Buyle FM, Vanholder RC, Hoste EA (2009) Epidemiology of infection in critically ill patients with acute renal failure. Crit Care Med 37:2203-2209

32. Gibney N, Hoste E, Burdmann EA, Bunchman T, Kher V, Viswanathan R, Mehta RL, Ronco C (2008) Timing of initiation and discontinuation of renal replacement therapy in AKI:

unanswered key questions. Clin J Am Soc Nephrol 3:876-880
33. Uchino S, Kellum JA, Bellomo R, Doig GS, Morimatsu H, Morgera S, Schetz M, Tan I, Bouman C, Macedo E, Gibney N, Tolwani A, Ronco C (2005) Acute renal failure in critically ill patients: a multinational, multicenter study. JAMA 294:813-818

34. Hoste EAJ, Schurgers M (2008) Epidemiology of AKI: how big is the problem? Crit Care Med 36:S1-S4 